Filol. Linguíst. Port., São Paulo, v. 17, n. 2, p. 619-640, jul./dez. 2015

http://dx.doi.org/10.11606/issn.2176-9419.v17i2p619-640

\title{
A subjetivação da identidade da criança em cenografias publicitárias
}

\author{
Children's identity subjectivation in publicity cenographies \\ Érika de Moraes* \\ Universidade Estadual Paulista, Bauru, São Paulo, Brasil
}

\begin{abstract}
Resumo: Este artigo discute a identidade da criança a partir da publicidade, sob o prisma da Análise do Discurso de linha francesa, que considera as condiçóes históricas de produção como intrinsecamente vinculadas aos discursos que circulam em uma determinada época. Para tanto, retoma uma propaganda de 1999 (de anúncio publicado na Revista Veja Kid+) e propôe uma análise de anúncios atuais (2015) veiculados na revista Vogue Kids, com base em suas cenografias. Assim, é possível investigar quais marcas discursivas se renovam e quais se mantêm no que se refere à construção da identidade da criança nos anúncios publicitários, por meio de um recorte histórico, permitindo localizar os discursos predominantes a respeito dessa identidade na história recente.
\end{abstract}

Palavras-Chave: Identidade. Criança. Publicidade. Discurso. Cenografias.

\begin{abstract}
This article discusses the identity of child in advertising directed to children, taking into account the theoretical and methodological conception of the French discourse analysis, which considers the historical conditions of production as intrinsically linked to the discourses that circulate in a given period. For this purpose, it retakes an analysis from 1999 (advertising published in Revista Veja Kid+) and it proposes an analysis of a current advertising (2015) published in Vogue Kids magazine, based on their
\end{abstract}

* Docente vinculada ao Departamento de Ciências Humanas da Faculdade de Arquitetura, Artes e Comunicação da Unesp, Bauru, SP, Brasil. Doutora em Linguística pelo Instituto de Estudos da Linguagem, IEL-Unicamp. Membro do Grupo de Pesquisa Fórmulas e Estereótipos: teoria e análise (FEsTA). E-mail: erika.moraes@faac.unesp.br 
cenographies. Thus, it is possible to investigate which are new discursive marks and which of them remains with regard to the construction of children's identity in publicity, by means of a historical approach, which allows locating the prevailing discourses about this identity in the recent history.

Keywords: Identity. Child. Publicity. Discourse. Cenographies.

\section{CONSIDERAÇÓES INICIAIS}

Sabemos que a comunicação com o público infantil exige cuidados especiais, dada a responsabilidade relacionada à formação da identidade nessa faixa etária. A criança não deve ser subestimada, ao mesmo tempo em que não deve ser tratada como "adulto em miniatura", o que parece ocorrer em casos polêmicos, a exemplo da revista Vogue Kids, edição de setembro de 2013, criticada e recolhida das bancas por determinação da Justiça, que considerou inadequada a veiculação de um ensaio sensual com modelos menores de idade (Portal Bol, 13/09/2014).

Na mesma linha, grife do apresentador Luciano Huck é investigada pelo Ministério Público por utilizar frase em camiseta infantil que pode caracterizar incentivo à pedofilia, com os dizeres "Vem ni mim que eu tô facin" (Diário Gaúcho, 05/03/2015). A interpelação da criança se dá, muitas vezes, portanto, a partir de ideais do mundo adulto, como o da sensualização e do incentivo ao consumo, quase sempre associados entre si.

Ao estudar a Revista Veja Kid+, publicação da Editora Abril que circulou de 1998 a 2000, constatamos que o ideal de consumo atravessava a interpelação da criança enquanto sujeito (Moraes, 2002). Um efeito contraditório, uma vez que a imagem de criança era construída discursivamente como incompleta em sua interação com a revista, que a caracterizava como alguém dependente da intervenção de processos de edição por parte de adultos. De forma supostamente lúdica e educativa, o adulto a orienta, a conduz, seja por intermédio de uma personagem caracterizada como a mascote Lorenzo (que comenta a publicação, "conversando" com a criança), seja por outros processos de edição como a categorização de assuntos por meio de ícones e divisóes editoriais. $\mathrm{O}$ ideal de consumo esteve sempre presente em toda a publicação, inclusive de forma menos explícita em reportagens jornalísticas e, obviamente, mais evidenciada no espaço publicitário.

Neste momento, faz-se pertinente retomar o caso de Veja Kid+ para, então, investigar a atuação da publicidade para o público infantil mais de uma década após

Moraes, E. A subjetivação da identidade da criança em cenografias publicitárias... 
este estudo. Quais as possíveis diferenças e semelhanças entre a publicidade para o público infantil nos últimos anos do século XX e na atualidade (2015)? Quais são as marcas discursivas que prevalecem na publicidade para o público infantil? Quais discursos, eventualmente, são modificados? Quais suas implicaçôes sobre a imagem de criança na atualidade? É sobre tais questionamentos que procuraremos discorrer.

\section{UMA VISÃO INTERDISCURSIVA SOBRE A SUBJETIVIDADE DA CRIANÇA}

O presente estudo se respalda em uma análise discursiva da publicidade dirigida ao público infantil, a partir de um ponto de vista fundamentado nos pressupostos teóricos e metodológicos da Análise do Discurso francesa (doravante AD). Objetiva-se investigar, fundamentalmente a partir do(s) discurso(s) dirigido(s) à criança, qual é a representação do chamado público infantil.

Como se sabe, a segmentação, isto é, a produção jornalística voltada para públicos específicos, é uma característica do jornalismo contemporâneo, seja na forma de revistas especializadas, seja em suplementos encartados nos jornais diários, constituindo uma das estratégias de marketing para aumentar o número de "consumidores" desses produtos. Assim, existem as publicaçóes especializadas em diversos tipos de assunto (moda, esporte, turismo, economia etc.) e dirigidas a diferentes públicos (feminino, masculino, negro, adolescente, gay, surfista etc.).

É nesse contexto que se inserem também os produtos voltados para o público infantil. A segmentação de público é, ainda, uma forma de marcar as diferenças e envolve um "jogo bastante complexo em que é possível assistir a vários embates em torno da imposição de sentidos e da interpelação de sujeitos” (Fischer, 2000, p. 78).

Ao abordar a questão das estratégias de linguagem da mídia e da produção de subjetividades, Fischer (2000) se questiona sobre que sujeitos estão sendo formados pela mídia. Segundo a autora, falar de subjetividade é tema obrigatório na contemporaneidade, mesmo em terrenos tradicionalmente voltados para o social, como é o caso dos meios de comunicação midiáticos, uma vez que o social e o individual são, hoje, lugares imbricados. E a mídia tem um marcante papel na produção de sujeitos na cultura, especialmente a partir de estratégias de linguagem e de direcionamento aos variados grupos sociais (cf. Fischer, 2000, p. 76).

Como demonstra a historiografia, a imagem de criança é culturalmente construída e pode ser muito diferente em diversas épocas e sociedades, o que se

Moraes, E. A subjetivação da identidade da criança em cenografias publicitárias... 
reflete nas artes (literatura, pintura etc.) e nos produtos oferecidos às crianças (brinquedos, roupas, entre outros).

Em História social da criança e da família, Philippe Ariès (1981) sustenta duas teses centrais. A primeira refere-se às sociedades tradicionais; a segunda, ao novo lugar assumido pela criança e pela família nas sociedades industriais. $\mathrm{O}$ autor toma como ponto de partida a sociedade medieval, na qual não existia o "sentimento da infância", entendido como "consciência da particularidade infantil" (Ariès, 1981, p. 57). A infância era considerada uma passagem breve e insignificante da vida. Logo após seus primeiros desenvolvimentos físicos, a criança era misturada aos adultos, partilhando de suas atividades. A transmissão de valores e conhecimentos aos mais novos se dava pelo que Ariès chamou de "aprendizagem", dado que não havia uma forma sistemática de educação assegurada pela família. Para o autor, a indiferença com a criança "era uma consequência direta e inevitável da demografia da época” (1981, p. 57). Sua morte era um fato absolutamente tolerável, que não despertava grande sensibilidade, já que ela poderia ser facilmente "substituída".

O primeiro sentimento existente em relação à criança é chamado por Ariès de "paparicação" - um sentimento superficial, dirigido à criança em seus primeiros anos de vida, quando era uma "coisinha engraçadinha" que divertia o adulto, servindo-lhe de passatempo como "um animalzinho, um macaquinho impudico" (Ariès, 1973, p. 10).

O autor considera ter havido uma "significativa mudança" que alterou esse quadro a partir do fim do século XVII: a "escolarização" substituiu a "aprendizagem", revelando a importância que se passou a atribuir à educação, além de um despertar para a especificidade da infância. A criança não mais se misturaria logo cedo à vida adulta - ela "foi separada dos adultos e mantida à distância numa espécie de quarentena, antes de ser solta no mundo" (Ariès, 1973, p. 11): trata-se do período escolar, que, na época, inclusive caracterizava-se pelo isolamento dos colégios internos, ao menos no caso de famílias pertencentes às camadas sociais mais altas.

Essa mudança se deu, por um lado, em razão de um movimento de moralização promovido por reformadores católicos e protestantes e, por outro, da "cumplicidade sentimental das famílias". A instituição familiar, nesse momento de valorização da vida privada, tornou-se "o lugar de uma afeição necessária" entre seus membros. A criança saiu de seu "antigo anonimato" e passou a ter importância central na família. Perdê-la ou substituí-la deixou de ser considerado um fato natural e passou a ser motivo de grande dor. Ariès aponta o fato de que essa "revoluçáo escolar e sentimental" tenha sido seguida, com o passar do tempo, de uma "reduçáo voluntária da natalidade, observável no século XVIII” (Ariès, 1981, p. 12). 
Algumas mudanças foram lentas. A correspondência entre idade e classe escolar, fundamental para a distinção da segunda infância, fixou-se progressiva e tardiamente, estabelecendo-se somente no início do século XIX. Além disso, lembra o próprio Ariès, até hoje (a observação se mantém atual até hoje), "nós falamos em começar a vida no sentido de sair da infância” (Ariès, 1981, p. 57), o que denuncia a consideração do caráter transitório desse período da vida.

Seguindo, com algumas restriçóes, essas teses, Priore (1999, p. 10) considera que, apesar das críticas que receberam, "as teses de Ariés instigam o pesquisador brasileiro a procurar suas próprias respostas”, desde que a historiografia internacional sirva de interpretação, mas não de "bússola" para nós. A autora ressalta que, no Brasil, tanto a escolarização quanto a emergência da vida privada chegaram tardiamente em relação à Europa. Além disso, ainda em nossos tempos, "o trabalho infantil continua sendo visto pelas camadas subalternas como 'a melhor escola"' (Priore, 1999, p. 10), o que torna a realidade brasileira, caracterizada pela "pobreza e a falta de escolarização”, distante da realidade europeia (Priore, 1999, p. 13-14).

De qualquer forma, um fator considerado por diversos pesquisadores como representativo de uma mudança crucial é que, enquanto antigamente as crianças cresciam misturadas aos adultos, hoje (e desde o fim do século XIX) suas histórias são constituídas separadamente, podendo-se perceber a "tendência crescente de separar o mundo das crianças do mundo dos adultos" (Souza, 2000, p. 94). O sentimento moderno da infância trouxe, portanto, como uma de suas principais consequências o "afastamento do adulto da criança”" (Souza, 2000), já que:

Outrora, sabia-se exatamente o significado da experiência, ela era sempre comunicada aos jovens. De forma concisa, em provérbios, ou de forma prolixa em histórias, muitas vezes como narrativas e lugares de tempos distantes. Em ambos os casos a autoridade da velhice era reconhecida e respeitada. Mas os tempos mudaram. Quem tentará, sequer, lidar com a juventude invocando sua experiência? (Souza, 2000, p. 94, com remissão a Walter Benjamin, 1996)

Nos tempos atuais, a valorização da criança é assegurada, do ponto de vista jurídico, pelo Estatuto da Criança e do Adolescente. A infância é consagrada como um período decisivo na vida do ser humano e torna-se impensável a indiferença dos tempos remotos. A defesa da vida de uma criança passou a ser táo natural quanto antes era sua morte. Tal valorização afeta os discursos sobre a criança e seus efeitos de sentido.

Moraes, E. A subjetivação da identidade da criança em cenografias publicitárias... 
Considerando o discurso como produto do interdiscurso, é possível identificar a presença dos discursos culturalmente tidos como "naturais" pelos adultos e que são, assim, direcionados à identidade da criança. Por meio da análise discursiva (no caso, de textos publicitários), pode-se apreender quais discursos são acionados e a quais formaçóes discursivas se relacionam (Pêcheux, 1975), uma vez que os sujeitos dizem o que dizem por estarem em determinada posiçáo.

Entende-se o discurso tal como concebido por Maingueneau, a partir de Foucault: "uma dispersão de textos cujo modo de inscrição histórica permite definir como um espaço de regularidades enunciativas" (Maingueneau, 2005a, p. 15). O discurso não é um sistema de "ideias", mas um "sistema de regras que define a especificidade de uma enunciação" (Maingueneau, 2005a, p. 19). Em outras palavras, situar-se historicamente num lugar permite dizer certas coisas e não dizer outras, já que as regras determinadas pelos lugares enunciativos impóem restriçóes ao dizer. Tais restriçóes levam em conta, também, o público a quem os discursos são dirigidos.

A $\mathrm{AD}$ se revela, portanto, um lugar pertinente para se pensar na questão da subjetividade no discurso. O sujeito do discurso não é um elemento neutro, mas também não é autônomo. O conceito de alteridade é trazido para o discurso: concepção do um através do(s) outro(s), o que pode ser apreendido por meio da contribuição de Authier-Revuz (1982), ao propor o conceito de "heterogeneidade(s) enunciativa(s)". Para a autora, as marcas de heterogeneidade mostrada - processos de constituição do sujeito, que inscrevem o outro na sequência do discurso - mostram uma espécie de "negociação" com a heterogeneidade constitutiva. Nosso trabalho é estudar como essa "negociação" entre as heterogeneidades pode resultar no discurso dirigido à criança. Uma vez que a heterogeneidade mostrada é concretamente representável no discurso, é com ela, naturalmente, que os meios de comunicação trabalham, sem, no entanto, considerarem esse conceito e sua contraparte - a heterogeneidade constitutiva do discurso.

\section{CENOGRAFIAS NO DISCURSO}

Em nosso trabalho, procuraremos descrever as cenografias apresentadas nas publicidades, dado que, conforme ressalta Maingueneau, o modo de dizer não é dissociado do conteúdo do dizer. A cenografia é interdependente do discurso que caracteriza um certo ethos, ou seja, uma imagem social que, ao mesmo tempo, constrói e legitima um discurso.

Moraes, E. A subjetivação da identidade da criança em cenografias publicitárias... 
Como mostra Maingueneau, as situaçóes de enunciação se constituem no quadro de uma "cena de enunciação", que não se confunde com um simples quadro empírico, mas "se constrói como cenografia por meio da enunciação" (2006, p. 47). Segundo essa concepção, "o discurso implica um enunciador, um co-enunciador, um lugar e um momento da enunciação que valida a própria instância que permite sua existência", sendo que a "cenografia é ao mesmo tempo dada e construída" (Maingueneau, 2006, p. 47).

Seguindo os conceitos de Maingueneau (2005b, p. 75), em nossas análises, a cena englobante, que corresponde ao tipo de discurso e a ele confere seu estatuto pragmático, é o discurso publicitário. A cena genérica, que é a "do contrato associado a um gênero, a uma 'instituição discursiva"', é caracterizada por um tipo específico de publicidade, a de revistas impressas. Já a cenografia é específica para cada caso, pois "não é imposta pelo gênero, ela é construída pelo próprio texto" (Maingueneau, 2005b, p. 75).

É importante ressaltar, com Maingueneau, que a cenografia não deve ser interpretada como simples cena ou quadro estável. "Na verdade é preciso concebêla ao mesmo tempo como quadro e como processo", ou seja, "o discurso implica uma certa situação de enunciação, um ethos e um 'código linguageiro' através dos quais se configura um mundo que, em retorno, os valida por seu próprio desenvolvimento" (2006, p. 47).

O leitor reconstrói a cenografia de um discurso com o auxílio de indícios diversificados, cuja descoberta se apoia no conhecimento do gênero de discurso, na consideração dos níveis da língua, do ritmo etc. ou mesmo em conteúdos explícitos. Em uma cenografia, como em qualquer situação de comunicação, a figura do enunciador, o fiador, e a figura correlativa do co-enunciador são associadas a uma cronografia (um momento) e a uma topografia (um lugar) das quais supostamente o discurso surge. (Maingueneau, 2005b, p. 77)

Assim, a cenografia, que comporta a construção de um ethos específico, entre outras coisas, amparado em situaçóes constituídas via estereótipos existentes, memória discursiva e interdiscurso, será descrita nas análises. Os gêneros do discurso publicitário, diferentemente dos gêneros "fechados" (como os formulários ou o despacho administrativo, que, por sua natureza, se reduz à cena englobante e à cena genérica) são de natureza tais que exigem a escolha de cenografias variadas. Portanto, é grande a diversidade de cenografias a que pode recorrer. 
É possível, inclusive, afirmar que o essencial no texto publicitário não é o gênero, mas a cenografia, uma vez que cada tipo de anúncio recorre a uma cena validada para promover (e vender) seu produto. A cena validada se constitui no paradoxo de ser, ao mesmo tempo, exterior e interior ao discurso que a evoca. Quanto mais investe na caracterização das cenografias a partir de tais cenas validadas, mais o discurso publicitário se aproxima de situaçóes que se constituem como objeto de desejo de seu público.

A cenografia, como o ethos que dela participa, implica um processo de enlaçamento paradoxal: desde sua emergência, a fala supóe uma certa cena de enunciação que, de fato, se valida progressivamente por essa mesma enunciação. A cenografia é, assim, ao mesmo tempo, aquela de onde o discurso vem e aquela que ele engendra; ela legitima um enunciado que, por sua vez, deve legitimá-la. (Maingueneau, 2005b, p. 77)

Vale lembrar que a noção de ethos - crucial para a (re)constituição da cenografia da qual participa e deriva - está diretamente ligada à enunciação, "não a um saber extradiscursivo sobre o enunciador" (Maingueneau, 2005b, p. 70). E "longe de situar-se na nascente do texto [...], o tom específico que torna possível a vocalidade constitui para nós uma dimensão que faz parte da identidade de um posicionamento discursivo" (Maingueneau, 2005b, p. 73). O ethos é, portanto, mais do que um meio de persuasão, sendo "parte constitutiva da cena de enunciação, com o mesmo estatuto que o vocabulário ou os modos de difusão que o enunciado implica por seu modo de existência” (Maingueneau, 2005b, p. 75).

Ainda que "crucialmente ligado ao ato de enunciação, não se pode ignorar, entretanto, que o público constrói representaçôes do ethos do enunciador antes mesmo que ele fale" (Maingueneau, 2005b, p. 71), daí a distinção entre ethos discursivo e pré-discursivo. Segundo o autor: "mesmo que o coenunciador não saiba nada previamente sobre o caráter do enunciador, o simples fato de que um texto pertence a um gênero de discurso ou a um certo posicionamento ideológico induz expectativas em matéria de ethos" (Maingueneau, 2005b, p. 71).

Ressaltamos, então, que, ao deparar com a publicidade nas revistas analisadas, o leitor tem, de antemão, um ethos pré-discursivo relacionado ao seu conhecimento sobre a publicação. Se a publicação, por exemplo, apresenta-se como divertida e lúdica para a criança, a publicidade tende a sustentar essa mesma imagem. No caso de Vogue Kids, revista especializada em moda, por exemplo, o ethos da criança fashion estará necessariamente presente.

Moraes, E. A subjetivação da identidade da criança em cenografias publicitárias... 


\section{UM CASO DE PUBLICIDADE NA REVISTA $V E J A ~ K I D+$}

Nossos estudos apontaram que o ideal de consumo tinha forte presença na Revista Veja Kid+. Além das propagandas implícitas no conteúdo jornalístico, há o espaço dedicado aos anúncios publicitários propriamente ditos, que constituem as propagandas explicitamente veiculadas na revista.

Os anunciantes da edição de outubro de 1999, base de nosso corpus, são Cartoon Network (canal de tevê por assinatura); chocolate Baton da Garoto; videogame Nintendo; marca Penalty (camisas, calçóes, tênis, chuteiras e bolas); CD e vídeo Sandy e Júnior (Promoção Sandy e Júnior); curativo Nexcare Tattoo; revista Disney Mania (do Grupo Abril); Graacc (Grupo de Apoio ao Adolescente e à Criança com Câncer - anúncio beneficente, que solicita doaçóes por meio de telefone ou depósito em conta corrente); merendas Parmalat.

A título de exemplificação da publicidade veiculada na Revista Veja Kid+, trataremos do anúncio do curativo Nexcare versão "Tattoo" (em formato de tatuagem), que se encontra na página 35 da edição do mês de outubro de 1999.

Conforme propóe Maingueneau, a análise discursiva deve compreender tanto os elementos verbais quanto os visuais, de acordo com a visão de uma semântica global. Ao colocar a concepção de uma semântica global, vinculada a uma prática discursiva e intersemiótica, o autor caracteriza a questáo do "público" nos seguintes termos: "a própria rede institucional desenha uma rede de difusão, as características de um público, indissociáveis do estatuto semântico que o discurso atribui" (Maingueneau, 2005a, p. 141).

O anúncio mostra uma criança, no caso, um menino, cujo ethos é representado como de "garoto moderno" (imagem de criança que perpassa toda a revista); são elementos da cenografia um skate nas costas e um curativo em forma de tatuagem no nariz. $\mathrm{O}$ menino não é estático, pratica uma atividade ativa (andar de skate) e, portanto, é legitimada a possibilidade de que pode machucar-se. Essa imagem visual carrega algumas informaçóes a respeito de noçóes de gênero (masculino/feminino) que são inculcadas desde a infância na mente dos indivíduos: quem costuma se machucar são os meninos, cujas "molecagens” são permitidas e até incentivadas. É comum a ressonância de uma "voz social" segundo a qual "menina tem que se cuidar mais para não cair, para não adquirir cicatrizes; joelho de menina esfolado é feio", precursora do mito da vaidade feminina (preocupação estética) e da postura correta exigida da mulher (que geralmente leva, por um lado, ao recato, por outro, à sensualização, como no exemplo de Vogue Kids citado anteriormente). Essa posição remete às noçôes de aceitabilidade (permissividade) da travessura (até

Moraes, E. A subjetivação da identidade da criança em cenografias publicitárias... 
mais que isso - vejam-se os discursos que buscam justificar o estupro!) para o sexo masculino e da preocupação feminina com a aparência. Não se trata, contudo, somente da exigência de uma preocupação feminina com a beleza (a menina deve apresentar-se sempre bem-vestida, sem arranhóes ou cicatrizes), mas, sobretudo, de um ideal de correção atribuído à mulher (aquela que tem "bons modos") e dela exigido. A escolha de um menino para o anúncio, portanto, remete a um discurso conservador, posição que conflita com o aparente aspecto de "modernidade" presente na publicidade e na publicação em geral.

Sabemos que os ideais culturais a respeito do que sejam os padróes de comportamento adequados para homens e mulheres são propagados desde a infância e transmitidos de geração a geração. A pesquisadora Montserrat Moreno lembra que o comportamento mais agressivo e menos contido do menino não é natural, mas imposto pelo modelo cultural vigente. Ela ressalta que:

Nos primeiros meses de vida é impossível detectar um nível de agressividade maior nos meninos que nas meninas, mas, à medida que crescem, a diferença vai-se acentuando. Devemos, pois, concluir que a agressividade é uma das características do modelo que se apresenta aos meninos e que tal característica não figura no que é apresentado às meninas (Moreno, 1999, p. 33).

A autora acredita que os produtos culturais veiculados pela mídia são propagadores desse modelo:

Nenhum livro de texto, nenhuma história em quadrinhos, nenhum programa de televisão, nenhum filme diz abertamente ao menino que ele deve ser agressivo, mas náo acreditamos que não tenham nenhuma influência sobre sua conduta agressiva. Cada um deles, de diferentes maneiras, está estimulando a agressividade no menino e reprimindo-a na menina náo de forma explícita e declarada, mas com a hipocrisia cúmplice de quem incita a fazer algo de que não quer ser acusado (Moreno, 1999, p. 33).

A questão a respeito dos lugares preconcebidos no imaginário coletivo quanto ao papel feminino também é observada pela educadora britânica Sue Palmer, de acordo com reportagem da Revista Crescer (Saleh, 2015). A especialista considera que, em detrimento de todos os avanços sociais, a menina ainda aprende que "seu papel é ter uma boa aparência e se comportar educadamente”. Tais padróes reforçam

Moraes, E. A subjetivação da identidade da criança em cenografias publicitárias... 
diferenças sociais entre os sexos, entre as quais a educadora destaca que "garotas têm mais facilidade para se socializar", o que tem o lado positivo de facilitar a interação social, mas também pode ser negativo se levar à "tendência a agradar as pessoas ou uma ansiedade constante a respeito da impressão que causa nos outros". A preponderância de um modelo consumista sustenta esses mesmos padróes:

No fim do século 20, acreditávamos avançar na igualdade de gênero, no fato de que as mulheres seriam economicamente independentes dos homens e, inclusive, sexualmente equiparadas (não mais seriam meros objetos sexuais). Porém, a influência do consumismo competitivo levou à auto-objetificação, que é a tentativa de alcançar a perfeição gastando tempo, esforço e dinheiro nessa busca. (Palmer apud Saleh, 2015).

É sobre esse tipo de estímulo à permanência de um modelo conservador, não explícito e não declarado, que está baseado esse anúncio publicitário (bem como outras seçôes de Veja Kid+), enquanto se explicita e se declara o ideal de modernidade que, segundo o imaginário da revista, faria de Veja Kid+ uma publicação avançada, pra-frente. Os discursos são, assim, conflitantes: a revista, por um lado, assume-se moderna/avançada e, por outro, dá sustentação a ideologias conservadoras. Como essas ideologias não são assumidas, a revista, aparentemente, camufla o conflito com a máscara da modernidade.

$\mathrm{O}$ anúncio também traz anexa uma amostra grátis de curativo, tatuagem em forma de um sapo, o mesmo desenho que está no nariz do garoto da foto. Amostras encartadas sáo uma tendência cada vez mais comum nas propagandas de revistas, representando (substituindo) um enunciado do tipo "use/experimente e comprove (a eficácia do produto)". Ou seja, a interpelação do destinatário está presente na mensagem não verbal, e assim funciona de forma até mais eficaz.

A tatuagem, por sua vez, é também representativa da imagem de criança "moderninha" (seria ainda mais no caso do adolescente). No entanto, ressalte-se, é mantido o tom "politicamente correto": tatuagem só de brincadeira, e não definitiva. Outro discurso conflitante, portanto. A revista aceita a tatuagem como um ornamento ousado, compatível com a imagem de criança moderna, contudo nada indica que a postura seria desprovida de preconceitos com relação às tatuagens definitivas. Não se defende, aqui, que a revista ou o anúncio deveria incentivar a tatuagem, apenas se coloca a questáo de que, em todo seu período de existência, 
cujas ediçóes acompanhamos, a revista não problematizou em outros espaços (como o das reportagens) a questão da tatuagem, apenas silenciou esta e outras questôes.

Quanto aos enunciados verbais, o anúncio traz os seguintes:

(1) Machucou? Faz uma tatuagem que passa.

(2) Peça já para a sua mãe os curativos Nexcare Tattoo. E colecione.

Em tais enunciados, um enunciador publicitário é porta-voz do sujeito institucional: a instituição responsável pelo anúncio (3M, cujo logotipo aparece ao final da propaganda). Sendo uma voz fiadora do discurso, interpela o interlocutor por meio do dêitico "você", embutido nas formas verbais "machucou" (terceira pessoa do pretérito perfeito do indicativo) e "faz", "peça" e "colecione" (formas imperativas dirigidas a uma segunda pessoa).

Há alguns discursos presentes nesses enunciados que indicam as formações discursivas (FDs) de que falam seus enunciadores e, consequentemente, de que formaçōes ideológicas provêm seus discursos. Em (1), são ecoados enunciados do tipo: "Quando casar sara" ou "Com beijinho passa". Ou seja, pequenos ferimentos podem ser resolvidos com cuidados simbólicos, como carinho, distração, entretenimento. $\mathrm{O}$ (2) é bastante comum no universo do (estímulo ao) consumo infantil, o que projeta outros enunciados típicos de criança, referindo-se aos seus objetos de desejo, como os do tipo: "Eu quero" ou "Compra pra mim".

O anúncio diz "Peça já". Ora, podemos questionar: o produto não é para ser utilizado quando a criança se machucar? Parece que não somente nessas ocasiōes. O segundo período acrescenta: "E colecione". Assim, o produto deixa de ser simplesmente um curativo e passa a ser um objeto de coleção, o qual deve ser comprado para que os diversos modelos (desenhos) de tatuagem sejam guardados (em vez de utilizados nos ferimentos). São, então, diversos os motivos para comprar "Tattoo", segundo o anúncio:

- É eficiente na cura de ferimentos (discurso científico);

- Funciona como um paliativo para os problemas, como vimos em (1), podendo aliviar a dor "psicológica" dos machucados (discurso psicológico);

- É objeto de diversão, brincadeira, coleção (discurso lúdico).

Cada motivo representa um tipo de discurso diferente, mas todos convergem ao incentivo do consumo do objeto anunciado. 
Os anúncios publicitários representam um espaço explícito de propagação (também de criação, de manutenção) da imagem de criança consumidora. Caparelli (1990) ressalta o papel ideológico desempenhado pela publicidade dirigida diretamente às crianças. $\mathrm{O}$ autor cita um estudo realizado por Charles Atkins, nos Estados Unidos, que, embora se refira à publicidade televisiva, traz conclusóes também pertinentes à impressa. Segundo esse estudo, as crianças que consomem as emissóes publicitárias:

Passam a gostar mais dos produtos anunciados, sejam eles brinquedos ou doces, pedindo-os aos pais, num crescente de conflitos e frustraçôes. Um corolário desse tipo de comportamento é a tendência em obter esses produtos a todo custo, integrando-os desde cedo aos aspectos consumistas da sociedade moderna (Caparelli, 1990, p. 67).

Conclui que a publicidade, considerada como um todo, "difunde uma ideia de homem, os valores de uma sociedade específica em que vale apenas o dinheiro, o domínio, o status, que no fundo são estereótipos, valores e comportamentos de uma determinada classe social" (Caparelli, 1990, p. 67).

Dentre os possíveis questionamentos pertinentes à publicidade para criança, podemos perguntar com Pereira et al. (2000, p. 106):

Que papel a linguagem publicitária desempenha na construção da subjetividade infantil? Que diálogos a publicidade constrói com a infância quando se apropria da sua imagem para vender produtos que, muitas vezes, sequer se destinam a ela? Que conceitos e valores a publicidade explicita na relação com o consumidor? É possível uma relação crítica do consumidor com as imagens veiculadas pela publicidade? Consumo e modos de ser são experiências indissociáveis ao sujeito contemporâneo? Que consequências trazem estas experiências no âmbito das transformações da cultura e do sujeito?

Acompanhando o raciocínio dos autores, podemos considerar que o produto divulgado num anúncio (Tattoo, por exemplo) deixa de ser apenas um produto (um curativo ou um brinquedo) e "assume um lugar de signo", sendo desejado 
"por todas as crianças", uma vez que possui-lo "significa ter status, ser admirada, respeitada e invejada por outros" (Pereira et. al., 2000, p. 107).

Os autores consideram que "o lugar que o mercado reservou para a criança tem sua história intimamente ligada aos novos reordenamentos das relaçôes entre adultos e crianças" (Pereira et al., 2000, p. 207). A criança que, inicialmente, era olhada como "filho de cliente que se relacionava com o mercado a partir do uso de bens materiais e culturais que se ofereciam a ela à margem da sua opiniáo", é, então, elevada ao "status de cliente, isto é, um sujeito que compra, gasta, consome e, sobretudo, é muito exigente" (Pereira et al., 2000, p. 207). Constatam que "a conquista desse status, bem como a autonomia do mercado destinado à infância, [...] acarreta novos modos de ser e de viver a infância: desejar, possuir, relacionarse com o dinheiro, gastar e saborear o poder de saber-se peça fundamental das estratégias de marketing (Pereira et. al., 2000, p. 107).

A elevação da criança da condição de "filho de cliente" para o "status de cliente" propriamente dito pode, em princípio, parecer um avanço no que tange à visão social de criança. Contudo a forma como o ideal de consumo é transmitido a ela implica uma suposta crença na passividade infantil. Nesse contexto, os autores expóem sua preocupação:

Embora a criança demonstre habilidades muito peculiares na sua relaçáo com o mundo material, criando outros sentidos para os objetos que possuem significados fixados pela cultura do consumo, parece difícil, também para ela, neste contexto, se manter criativa e inovadora em suas formas de pensar e agir no mundo. A criança é transformada pela mídia no modelo ideal de consumidor. Se, por um lado, ela não é considerada socialmente como um ser completo, por outro, na perspectiva de sua inserção na cultura, a criança é plena para o exercício do consumo (Pereira et. al., 2000, p. 110, grifo nosso).

Desse modo, a imagem de criança torna-se ambígua: por um lado, ela é um ser socialmente incompleto, por outro, um ser pleno para o exercício do consumo. Ora, são constataçôes contraditórias. Se ainda não é plena para o exercício da cidadania (ainda não exerce todos os direitos e deveres de um cidadão adulto: não vota, não pode se candidatar a um cargo público, não pode dirigir, não pode ser presa) é porque se supóe que ela não tem discernimento para tanto. É incoerente, assim, que seja considerada uma consumidora plena (pois a mesma criança que supostamente não tem discernimento o teria para escolher os bens que vai

Moraes, E. A subjetivação da identidade da criança em cenografias publicitárias... 
adquirir?). Se se considera que é socialmente incompleta (sujeitos incompletos não têm atividades "livres", independentes), conclui-se que a incompletude da criança - que a torna inapta à plena atuação enquanto agente social, mas permite-lhe o exercício do consumo - acarreta, como consequência, um papel de consumidor passivo e bastante influenciável.

\section{A PUBLICIDADE EM VOGUE KIDS}

A revista Vogue Kids é encartada bimestralmente com a Vogue Brasil, da Editora Globo (ou seja, a cada duas ediçóes, a Vogue de adultos publica, também, a Vogue Kids). Delimitamos, para análise, as publicidades veiculadas na edição 23 de Vogue Kids, que acompanha a edição 440 de Vogue, veiculadas no mês de abril de 2015. Por acompanharmos as ediçóes da revista, sabemos que as publicidades desta edição são representativas das demais.

Consideramos que o período de tempo decorrido entre nossa primeira análise (de Veja Kid+) e o da publicação atual seja um recorte interessante para compreender os discursos que se modificam e/ou aqueles que se mantêm em relaçáo à identidade da criança na história recente.

Optamos por uma descrição mais geral da publicidade da revista como um todo e, ao final, propomos nos ater em um anúncio específico, da DolceむGabana, escolhido pela posição privilegiada que ocupa (a contracapa - ou quarta capa -, visível mesmo para aqueles que não têm acesso ao interior da revista) e por representar uma espécie de síntese de todos os outros e, ao mesmo tempo, algumas rupturas, conforme mostraremos.

Trata-se de uma edição com cem páginas (capas incluídas), cuja capa frontal (Capa 1) apresenta um menino e uma menina, vestidos com camisa branca e saia vermelha (ela) ou jeans com moletom vermelho amarrado na cintura (ele), caracterizados com um visual inspirado nos toureiros espanhóis. Como é típico dos editoriais de moda, não se trata de um figurino "fantasia", mas de uma inspiração aplicada em visuais razoavelmente acessíveis ao dia a dia, do ponto de vista da usabilidade, embora de marcas caras. A expressão das crianças é pueril, em nada lembrando o ensaio sensual que causou problemas à publicação em 2014.

Ao contrário do objeto de nosso estudo anterior (Veja Kid+), Vogue Kids não é direcionada exatamente à criança, mas a uma máe que gosta de moda e pretende inserir os filhos também nesse universo, o que não impede que a revista seja folheada e apreciada por crianças que tenham acesso à publicação. 
No presente estudo, optamos por trabalhar exclusivamente com as publicidades veiculadas nesta edição. Não tratamos, neste trabalho, da publicidade embutida no conteúdo apresentado como jornalístico, o que não implica a desconsideração dessa presença, especialmente nos chamados editoriais de moda, que mesclam divulgação de informação de moda com exposição de marcas.

As páginas duplas iniciais trazem anúncio da marca amime, somente com meninas (duas modelos). O cenário é o de um parque de diversóes e uma das garotas está em um carrossel. Embora as roupas tenham um toque divertido, assim como o cenário, bem poderiam ser entendidas como o visual de uma mulher jovem em miniatura, já que a jovialidade é uma característica marcante da moda atual. O discurso presente no cenário e no visual descontraídos (bases constitutivas da cenografia do anúncio) conflita com a postura "comportada" das meninas, que remete ao "bom comportamento" esperado do sexo feminino.

Por sua vez, as páginas duplas seguintes trazem o anúncio da marca Acostamento Kids, somente com meninos (quatro modelos). Todos são caracterizados com um visual esportivo: polo ou camiseta, calça jeans, cinto e tênis; um deles usa boné e segura uma bola de futebol americano, outro carrega um taco de beisebol. Ao contrário do cenário do anúncio anterior (o parque de diversóes), neste caso a cenografia é mais sóbria: os meninos estão diante de um carro preto (dois deles sentados no capô), cuja marca não é possível visualizar, mas percebe-se que se trata de um veículo de alto padrão. Ao redor, o cenário é uma rua e um gramado desfocado, ou seja, um fundo neutro, o que contribui para pôr em destaque os figurinos dos meninos. Esses primeiros dois anúncios já reforçam um imaginário corrente sobre o masculino e o feminino: enquanto as meninas são mais divertidas, coloridas, expressivas (embora devam ser comportadas), os meninos são mais sóbrios, esportivos, despojados. Enquanto o visual delas é mais estilo "boneca" (para ficar "arrumadinha"...) o deles, mais esportivo e confortável, permite movimento, "molecagem". Nenhuma das crianças dos anúncios mencionados é negra ou oriental, por exemplo.

O próximo anúncio, publicado na página 17, é da marca Green by missako e traz um menino e uma menina: ele, com bermuda, camisa e jaqueta; ela, com vestido, meia-calça e lenço amarrado na cabeça. $\mathrm{O}$ visual de ambos parece confortável pelo aspecto dos tecidos. Inevitavelmente, são reforçados estereótipos de masculinidade (bermuda, que permite movimentos livres) e feminilidade (vestido e laço, que exigem comportamento mais cuidadoso). Não se trata, aqui, de criticar esses lugares sociais ou defender que deveriam ser necessariamente subvertidos, é 
apenas uma constatação. O fundo é neutro, uma espécie de cortina em estampa verde.

A página 21 traz anúncio da marca $1+1$, com uma menina usando vestido, casaco e acessório de cabelo, em tons rosa e azul, predominância de estampas florais - ou seja, na caracterizaçáo visual, há manutenção de aspectos associados à feminilidade. A página 27, por sua vez, traz anúncio da marca Colcci Fun, voltada a pré-adolescentes. Os modelos deste anúncio (um garoto e uma garota) aparentam ser mais velhos que os dos anteriores. O cenário é um ponto de ônibus em estilo londrino com os dizeres Wait for Fashion Signal. O visual de ambos é mais equilibrado entre si; mesmo assim é possível observar marcas dos discursos naturalizados como do masculino e do feminino. Ele veste bermuda jeans, camiseta, moletom e tênis, num visual bem esportivo. Ela mantém o estilo esportivo, usando short jeans, camiseta, camisa, moletom amarrado na cintura e bota. A predominância é da cor azul, porém, se a feminilidade náo está marcada pela cor estereotipicamente feminina (o rosa), marcas mais sutis a representam: a estampa delicada da camisa, a bota azul com franjas (em oposição ao tênis do menino). O equilíbrio maior deste anúncio, em comparação ao de outras marcas mais infantis, pode se justificar pelo fato de que os adolescentes, a quem o anúncio se dirige, são mais questionadores em relação aos estereótipos vigentes. De qualquer forma, o anúncio se sustenta na oscilação entre a manutenção e a quebra de estereótipos, já que, por um lado, busca afinar-se com discursos contemporâneos e, por outro, mantém aspectos conservadores, representados por certas características, como a delicadeza, associadas à feminilidade.

A página 33 traz anúncio da marca Matinée, com duas meninas em estilo bem "boneca", uma delas loira, a outra moreno-clara com cabelos cacheados, o que traz um pouco mais de diversidade ao anúncio - mais uma vez, trata-se de uma tentativa de ruptura com discurso conservador, mas que se dá apenas na superfície. A primeira usa camiseta e saia branca com babados, com acessório de cabelo também branco. A segunda, um visual composto por short, camiseta e jaqueta, todas as peças em tons dourados e um enorme laço preto no pescoço. O cenário é bastante neutro, quase totalmente branco, constituindo a imagem das crianças de maneira estática, como em um quadro, sem remissão à brincadeira - exceto pelo visual de bonecas, que são elas próprias. A cenografia, portanto, respalda-se na estaticidade, no bom comportamento, o que é característico de um discurso conservador em relação à mulher.

Na página 35 vê-se um anúncio de acessórios para alimentação do bebê, da marca Mam, evidência de que os produtos são mais direcionados às mães leitoras de Vogue do que às crianças propriamente. A página 37 traz mais uma modelo 
em estilo "boneca", com anúncio da marca Carinhoso. Ela veste saia xadrez, blusa, casaco longo (sobretudo) de cor rosa, gorro cor violeta e bota de cano médio, novamente reforçando marcas de feminilidade. $\mathrm{Na}$ página 39 encontra-se anúncio da marca Veggi, com quatro crianças (dois meninos e duas meninas), ambos os sexos com visuais coloridos, sendo o dos meninos um pouco mais sóbrio. Os cabelos dos modelos são nitidamente produzidos por cabeleireiro, com penteado e babyliss para as meninas, e um "arrumado para parecer desarrumado" para os meninos. A oscilação entre a manutenção e a ruptura com estereótipos também se faz presente, uma vez que se procura representar a diversidade (ambos os sexos são "coloridos"), ao mesmo tempo em que se reforça um discurso conservador (os meninos são mais despojados).

A página 40 traz anúncio da marca Gats Little Shoes, com duas meninas caracterizadas como dançarinas, vestidas em tons de preto e dourado. Neste último anúncio, a imobilidade se repete, reforçada pela moldura de um quadro da nobreza fixado na parede, como se fosse o centro de três molduras, sendo as meninas as outras duas. Vale observar que o uso das cores preto e dourado, num primeiro momento, pode simbolizar uma atualização em relação aos tons delicados tipicamente associados ao feminino (o rosa, o violeta, por exemplo). Por outro lado, reforça a sensualização da mulher, uma das marcas de discurso estereotipado em relação ao feminino. Nota-se, portanto, que o discurso publicitário contemporâneo se respalda nesse embate entre o supostamente inovador e o conservador.

A página 88 traz um anúncio de aplicativo para mulheres grávidas, da Revista Crescer, também da Editora Globo, mais um direcionamento às mães das crianças. Reforçando essa ideia de produto dirigido aos pais, na página 95 encontra-se um anúncio de cadeiras infantis para automóvel, da marca Dzieco.

Por fim, o anúncio da contracapa (ou quarta capa), da DolceðGabana, não deixa de ser uma espécie de síntese de todos os outros, uma vez que mistura diversos personagens: oito crianças (quatro meninos e quatro meninas) e três adultos (dois homens e uma senhora idosa) que interagem com as crianças: os dois homens seguram, cada um, um menino no colo, numa postura paternal, enquanto a senhora é mais estática no anúncio, podendo representar uma figura de avó, quase desfocada por uma sombra da fotografia. Chama a atenção o fato de que, além de equilibrar o número de meninos e meninas, o anúncio procurou diversificar as aparências: há brancas loiras, negras, brancos loiros, negros e uma menina oriental. Como costuma acontecer no universo da moda, nota-se a ausência de uma modelo de pele negra escura, o limite parece ser o "mulato".

Moraes, E. A subjetivação da identidade da criança em cenografias publicitárias... 
Representaçóes do masculino e do feminino aparecem nas vestimentas: as meninas usam vestidos coloridos, saias com babados e predominância de estampa em poás (tendência da estação), enquanto o visual dos meninos é mais sóbrio e esportivo - tanto que ocupam mais um plano de fundo, enquanto as meninas se destacam em posição de frente na foto. Um dos garotos está, inclusive, de costas, a fim de mostrar os detalhes da parte de trás de seu moletom. Duas das garotas carregam mochila-carrinho, uma delas preenchida com dois ursos de pelúcia. $\mathrm{O}$ fundo é neutro: uma parede e uma porta em estilo "madeira demolição". Os calçados pouco se destacam, já que há predominância de sombra nos pés.

O conjunto da obra transmite a ideia de "família feliz" e, ao mesmo tempo, rompe com a cenografia tradicional, já que não há, por exemplo, a figura da mãe, o que remete à simbologia das diversificações das famílias contemporâneas, podendo haver crianças criadas somente pela avó, por um dos pais etc. $\mathrm{O}$ anúncio é bastante significativo pelo diálogo conflitante com o interdiscurso: ao mesmo tempo em que reforça ideologias relacionadas ao masculino (sóbrio) e ao feminino (enfeitado), busca inserir-se na contemporaneidade do "politicamente correto" ao procurar explorar a diversidade na caracterização das personagens. As marcas de diversidade (presença de meninos e meninas; peles brancas e negras; crianças e adultos) funcionam como "marcas de heterogeneidade mostrada" que negociam com uma "heterogeneidade constitutiva" inerente ao discurso e, a rigor, indemonstrável (cf. Authier-Revuz, 1990).

Em outras palavras, caracteriza bem a oscilação entre a manutenção e a quebra de estereótipos que, de maneiras eventualmente mais sutis, aparece também nos outros anúncios da mesma edição. Esse busca afinar-se com o interdiscurso contemporâneo, que, a rigor, bloqueia formaçôes discursivas preconceituosas: são marcantes, atualmente, os movimentos que pregam os direitos e o empoderamento das mulheres, da população negra ou de outros grupos oprimidos ao longo da história. No entanto a própria existência desses movimentos (e, diga-se, também das vozes que a eles se contrapóem) revela que esses grupos ainda necessitam lutar por seus espaços. Na busca de conciliar-se com essa "política" contemporânea é que o anúncio explora as marcas de heterogeneidade, silenciando, na superfície, o modelo da família tradicional (pai, mãe e filhos). Ao mesmo tempo, porém, a retratação desses personagens de maneira diversificada se apoia em marcas do discurso tradicional, no modo de vestir-se ou portar-se. Assim, embora a diversidade abra falhas no suposto discurso tradicional, a heterogeneidade constitutiva aponta para uma formação discursiva ainda presa a uma ideologia conservadora. A suposta unidade do anúncio camufla uma relação de contradição, 
que vem à tona na análise, já que há afinidade com a quebra de estereótipos, característica dos discursos contemporâneos, e manutenção de formações preconceituosas.

Descritos os anúncios desta edição, por meio de suas cenografias, é possível afirmar que muitos deles flutuam, como vimos, entre a manutenção e a quebra de estereótipos, alguns tendendo mais para um dos lados. O último anúncio descrito sintetiza esse aparente conflito nas formações discursivas dominantes no interdiscurso de nossa sociedade contemporânea.

Assim como o curativo Nescare (do anúncio de Veja Kid+), a moda é apresentada à criança não apenas como um produto, mas como signo desejado. Possuir as roupas publicadas em Vogue Kids significa ter status, ser admirado e invejado por outras crianças (cf. Pereira et. al., 2000, p. 107). Ainda que as diversidades apareçam na variedade de modelos infantis que incorporam a personalidade desejante da criança fashion - variedade dentro de certos limites, aliás -, sua subjetividade é respaldada em valores da sociedade de consumo. Nesse aspecto fundamental, portanto, o discurso se mantém conservador. Pequenas rupturas são ainda rasas, predominando estereótipos sobre o imaginário esperado a respeito das identidades infantis embasados em identidades de gênero.

\section{CONSIDERAÇÓES FINAIS}

Quinze anos e meio é o tempo que separa cronologicamente as duas publicaçóes analisadas. Assim, parece natural que as evidências de estereótipos, especialmente em relação ao masculino e ao feminino, sejam menos sutis no primeiro produto. Afinal, a sociedade caminha cada vez mais para a vigilância em relação a discursos potencialmente preconceituosos.

No entanto, por definição, o discurso é ideológico e a informação circula por meio do diálogo com a interdiscursividade. Dessa forma, é praticamente impossível desvencilhar-se de visóes estereotípicas das identidades de gênero ou da criança. A sociedade atual "aceita" a diversificação de comportamentos; por exemplo, a menina pode vestir short e ter uma atitude mais "moleca", porém, quando isso ocorre, ela é assim descrita como alguém que se aproxima de características masculinas, reforçando que se trata de identidades naturalizadas (tidas como naturais), o que vem corroborar a ideia de que há um ethos pré-discursivo culturalmente instituído a respeito de ser homem ou mulher.

Moraes, E. A subjetivação da identidade da criança em cenografias publicitárias... 
Percebem-se algumas mudanças no sentido de atualizar as cenografias constitutivas da identidade da criança no espaço publicitário, as quais contemplam, na publicidade contemporânea, mais marcas de diversidade. Essa ruptura é, porém, ainda rasa, uma vez que os discursos se fundamentam num ideal de consumo pouco inovador.

\section{REFERÊNCIAS}

Ariès P. História social da criança e da família. 2a ed. Rio de Janeiro, LTC, 1981.

Authier-Revuz J. Heterogeneidade(s) enunciativa(s). In: Orlandi EP, Geraldi JW, organizadores. Caderno de Estudos Linguísticos. Celene M. Cruz e João Wanderley Geraldi, tradutores. Campinas, IEL/Unicamp, V.19, jul/dez. 1990 [1982].

Caparelli S. Televisão, programas infantis e a criança. In: Zilberman R, organizadora. A produçáo cultural para a criança. Porto Alegre: Mercado Aberto, 4a ed., 1990.

Diário Gaúcho. MP vai investigar grife de Luciano Huck por camiseta que incentivaria pedofilia. Publicada em 05 mar. 2015. [citado em mar. 2015]. Disponível em: http:// migre.me/oUcOH

Fischer RMB. Mídia, estratégias de linguagem e produção de sujeitos. In: Candau VM, organizadora. Linguagens, espaços e tempos no ensinar e aprender. Encontro Nacional de Didática e Prática de Ensino (ENDIPE). Rio de Janeiro: DP\&A, 2000.

Maingueneau D. Gêneses do discurso. Bruxelles: P. Mardaga. Sírio Possenti, tradutor. Curitiba (PR): Criar Ediçôes: 2005a. [1984].

Maingueneau D. Ethos, cenografia, incorporação. In: Amossy R. Imagens de si no discurso. São Paulo (SP): Editora Contexto, 2005b.

Maingueneau D. Cenas da enunciação. Sírio Possenti e Maria Cecília Perez de Souza-eSilva, organizadores. Curitiba: Criar, 2006.

Moraes E. O imaginário da criança no discurso jornalístico: uma análise da Revista Veja $\mathrm{Kid}+$ [dissertação]. Campinas (SP): Universidade Estadual de Campinas, Instituto de Estudos da Linguagem, 2002.

Moreno M. Como se ensina a ser menina - o sexismo na escola. Campinas: Unicamp/ Moderna, 1999.

Pêcheux M. Semântica e Discurso: uma crítica à afirmação do óbvio. Campinas: Unicamp, 1990 [1975]. 
Pereira RMR et al. Ladróes de sonhos e sabonetes: sobre os modos de subjetivaçấo da infância na cultura do consumo. In: Souza SJ, organizadora. Subjetividade em questão: a infância como crítica da cultura. Rio de Janeiro: 7 Letras, 2000.

Priore MD, organizadora. História das crianças no Brasil. São Paulo: Contexto, 1999.

Portal de notícias Bol. Justiça determina recolhimento de Vogue Kids com ensaio sensual de crianças. Publicada em 13 set. 2014. [citado em mar. 2015]. Disponível em: http:// zip.net/bnpx $2 \mathrm{j}$

Saleh N. O desafio de educar meninas. Revista Crescer. [citado em mar. 2015]. Disponível em: http://revistacrescer.globo.com/Criancas/Comportamento/noticia/2015/03/o-desafiode-educar-meninas.html

Souza SJ. Infância, violência e consumo. In: Souza SJ (org.). Subjetividade em questão: a infância como crítica da cultura. Rio de Janeiro: 7 Letras, 2000.

Recebido em: 05/09/2015

Aceito em: 30/11/2015

Moraes, E. A subjetivação da identidade da criança em cenografias publicitárias... 